\title{
Demographic Dividends, Dependencies, and Economic Growth in China and India*
}

\author{
Jane Golley \\ The Australian Centre on \\ China in the World \\ The Australian National \\ University \\ H.C. Coombs Building (\#9), \\ Room 4221 \\ Canberra, 0200, ACT \\ jane.golley@anu.edu.au
}

\section{Rod Tyers}

Business School

The University of Western

Australia and

Centre for Applied

Macroeconomic Analysis (CAMA)

College of Business and

Economics

The Australian National

University

The University of Western

Australia (M25I)

35 Sterling Highway, Crawley Perth, 6009, Western Australia rod.tyers@uwa.edu.au

\begin{abstract}
The world's two population giants (China and India) have undergone significant, and significantly different, demographic transitions since the 1950s. The demographic dividends associated with these transitions during the first three decades of this century are examined using a global economic model that incorporates full demographic behavior and measures of dependency that reflect the actual number of workers to non-workers, rather than the number of working-aged to non-working-aged. Although much of China's demographic dividend now lies in the past, alternative assumptions about future trends in fertility and labor force participation rates are used to demonstrate that China will not necessarily enter a period of "demographic taxation" for at least another decade, if not longer. In contrast with China, much of India's potential demographic dividend lies in waiting for the decades ahead, with the extent and duration depending critically on a range of factors.
\end{abstract}

\section{Introduction}

There is a growing body of evidence to suggest that the potential "dividend," "gift," or "bonus" associated with a country's demographic transition toward a population dominated by people of working age can be quite substantial (Bloom and Williamson 1998; Bloom, Canning, and

* Funding for the research described in this paper is from Australian Research Council Discovery Grant No. DP0557889. Thanks to participants at the Asian Economic Panel meeting for their valuable comments and suggestions, and particularly to Sisira Jayasuriya and Xiaojing Zhang for their careful reading of the paper. Any remaining errors are of course our own. 
Sevilla 2002). Perhaps no country has benefited more from this transition than China: according to some estimates, demographic change can explain up to a quarter of China's record-breaking pace of economic growth during the last two decades of the 20th century (Cai and Wang 2005; Feng and Mason 2005). Yet, as noted by the Asian Development Bank (ADB 2011, 38), "The demographic dividend is not, however, an automatic consequence of demographic changes. Rather, it depends on the ability of the economy to productively use its additional workers-the 'East Asian Miracle' is a case in point." For India, with its slower and later demographic transition, much of the potential demographic dividend lies ahead, although whether it can capture anything like the economic benefits of China's more dramatic post1970s demographic transition remains to be seen.

Most of the empirical research attempting to measure the effects of the demographic transition on economic growth focuses on the declines in dependency ratios that follow from falling fertility rates and the consequent rise in the ratio of the workingaged to non-working-aged in a given population (Bloom and Williamson 1998; Bloom, Canning, and Malaney 2000; Bloom, Canning, and Sevilla 2002; Bloom and Canning 2005a; Cai and Wang 2005; Bloom et al. 2007). Cai and Wang (2005) use this measure to conclude that China's demographic dividend will come to an end in 2015. As the ADB $(2011,44)$ notes, however, "The value of an additional worker in the economy varies by age, educational attainment, work experience, and the distribution of workers across industries and occupations, among other things; it is also circumscribed by labor market and institutional parameters, such as labor force participation rates, unemployment rates, working hours, productivity, asset accumulation (such as from pension funds), and labor laws."

For this reason, the ADB use the slightly more refined concept of an "economic support ratio," which is the inverse of a dependency ratio that takes into account agespecific labor incomes in a given base year to age-specific consumption expenditures in the same year. Using this measure, they show that China's economic support ratio will peak in 2015 and India's will peak in 2042. By taking into account the impacts on labor force participation rates, capital accumulation, and total factor productivity, the ADB projections reveal that China can expect to receive positive growth benefits from its changing demographic structure to 2020, with only a slight "demographic tax" (a reduction of per capita GDP by only 0.8 percentage points) occurring between 2020 and 2030. For India, significant benefits to growth are expected for the period 2011-20 and 2021-30 (with the changing demographic structure adding 1.1 and 0.85 percentage points to annual real per capita growth rates, respectively). 
Our paper takes an alternative approach to projecting the paths of China's and India's dependency rates and their growth consequences. We use a model of the global economy that disaggregates regional households by age and sex and that incorporates full demographic behavior to project economic and demographic change through to 2030. The results confirm that India's demographic change in the next two decades could yield significant (although not gigantic) potential gains to future real per capita income, whereas for China these gains are largely in the past. The more critical point, however, is that the timing and duration of the demographic dividends in both countries is influenced by a number of factors, as we demonstrate using alternative assumptions about future trajectories for fertility and labor force participation rates in both countries.

The paper is organized as follows. Section 2 discusses the various links between demographic transition and economic growth in the context of China and India. In Section 3, the composite model is described and the baseline scenario for the global economy to 2030 is presented. Section 4 presents the results of simulations that make reasonable alternative assumptions about fertility rates and labor force participation rates in each country. An alternative "constant population structure" scenario is then introduced to isolate the demographic dividends to be enjoyed by the two countries in the first three decades of the 21st century. Section 5 offers conclusions.

\section{Fertility decline and demographic transition}

China's exceptional economic growth and development during the last 50 years has been accompanied by equally remarkable demographic change. Rapid drops in mortality and fertility rates ushered in the most rapid "demographic transition" experienced at any time anywhere in world history. The demographic transition to slower population growth has been profoundly affected by China's family planning policies, culminating in the one-child policy. Yet fertility rates would have declined anyway, affected as they have been in China's Asian neighbors by urbanization, female education, increases in labor-force participation rates, improved lifeexpectancy of newborn children, high parental costs of a competitive education system, and myriad socioeconomic factors. Indeed, India's fertility rates have also declined steadily since the 1970s. The relatively slow speed of this decline has been among the factors that have delayed India's demographic transition, however, particularly when contrasted with China's.

Figure 1 depicts the crude birth rates and death rates for China and India between 1950 and 2030 (actual data through to 2010 and projections thereafter). China's 


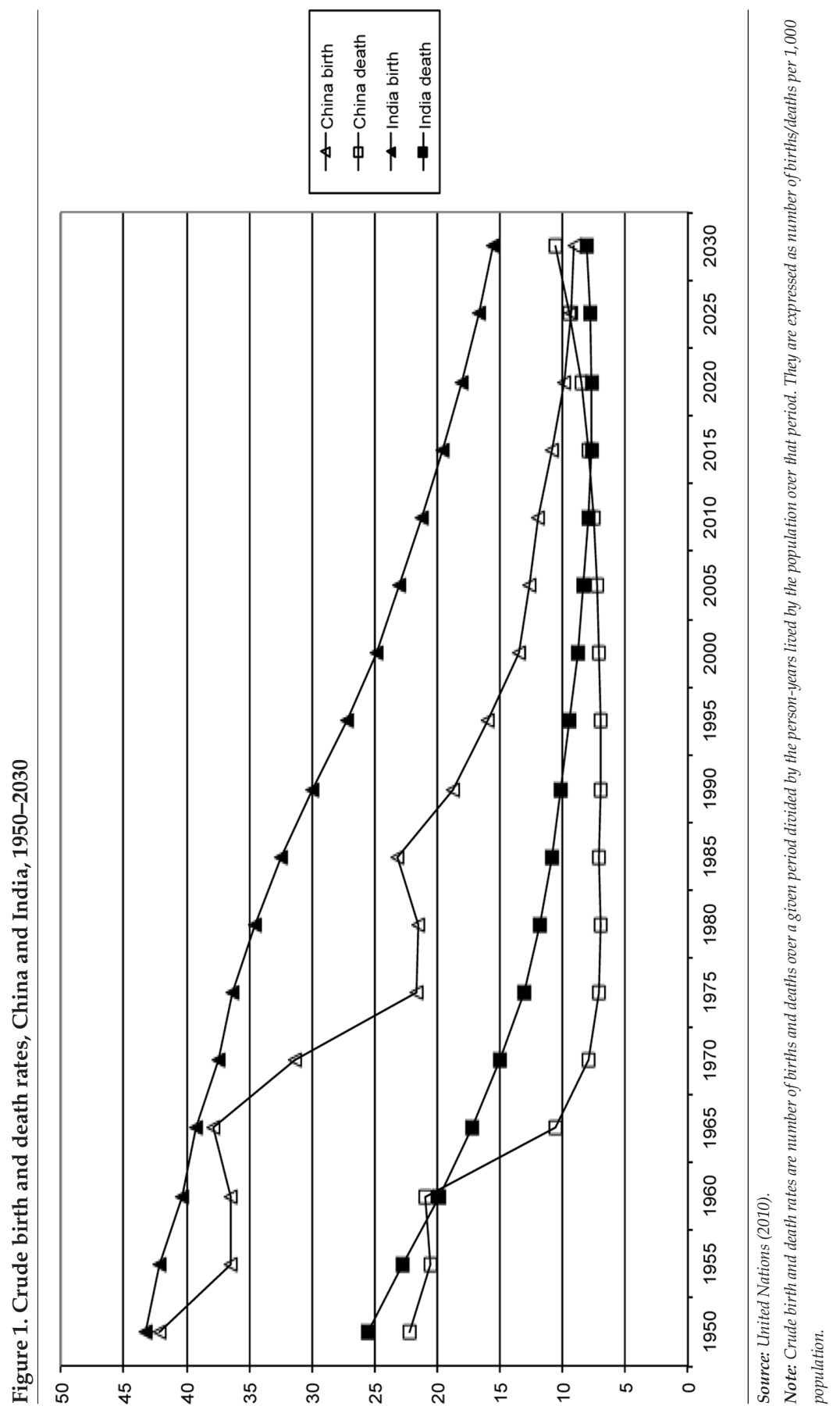


Figure 2. Youth and aged to working-aged population ratios, China and India, 1950-2030

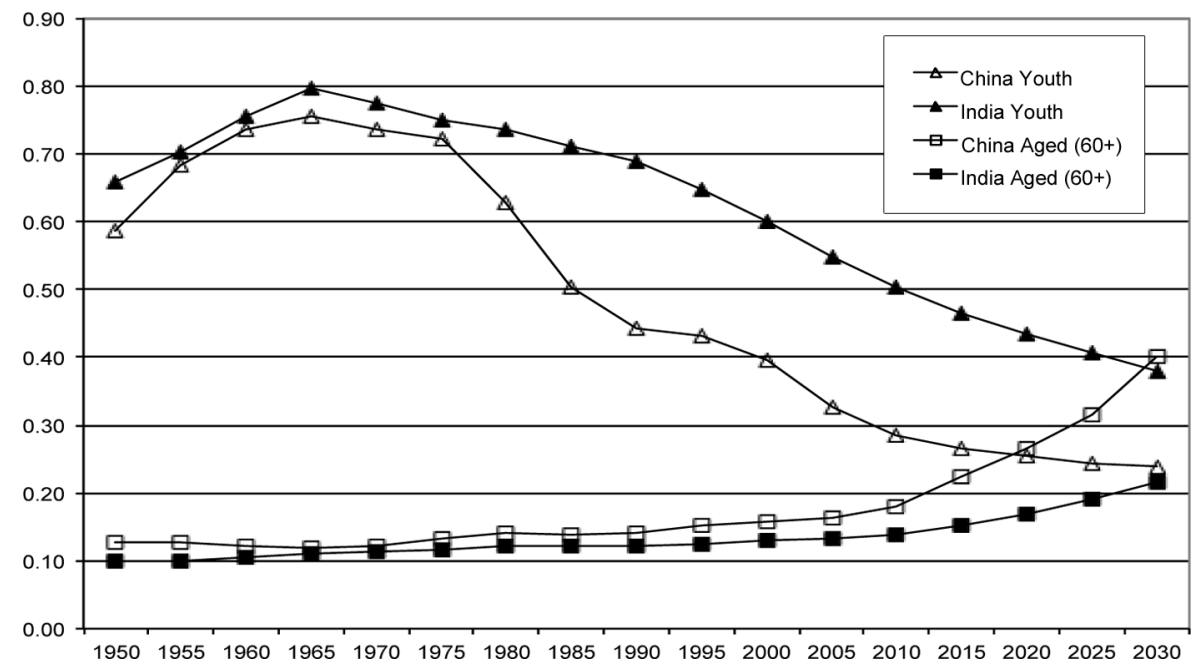

Source: United Nations (2010).

Note: Population projections based on medium fertility variant. Youth dependency ratio is number of youth (0-14 years) divided by the number of working-aged (15-59 years) in the total population. Aged dependency is number of aged (60+) divided by the number of working-aged (15-59 years) in the total population.

transition began in the early 1950s, with the death rate falling dramatically from 25 (per 1,000) in 1950 to 11 in $1965 .{ }^{1}$ Infant mortality improved dramatically during this time, although birth rates remained high until $1965,{ }^{2}$ falling steadily thereafter from 37 (per 1,000) in 1965 to 22 in 1980, by which time the death rate had fallen to 7.3. Since 1980, the birth rate continued to fall while the death rate changed only slightly, ranging between 6.6 and 7.5 during the period 1980 to 2010. As the figure shows, from nearly identical birth and death rates in 1950, China recorded a more rapid decline in its death rate followed by a more rapid decline in its birth rate, resulting in a more compressed and earlier transition than India.

Figures 2 and 3 illustrate the changing age structure of the Chinese and Indian populations during the period 1950-2030, using United Nations (2010) data for the

1 The use of five-yearly data smooths over the demographic disaster of Mao's Great Leap Forward, which, according to the National Bureau of Statistics (2000), resulted in death rates peaking at 25 in 1960. They recovered soon thereafter, however, and had fallen to 9.5 in 1965.

2 Infant mortality fell from 195 (per 1,000) births in 1950-55 to 121 in 1960-65 (United Nations 2010). As seen in the figure, the Great Leap Forward had a strong impact on birth rates as well. According to the National Bureau of Statistics (2000), these fell to a low of 18 in 1961 and then peaked at 43 in 1963. 
Figure 3. Working-aged to non-working-aged ratio, China and India, 1950-2030

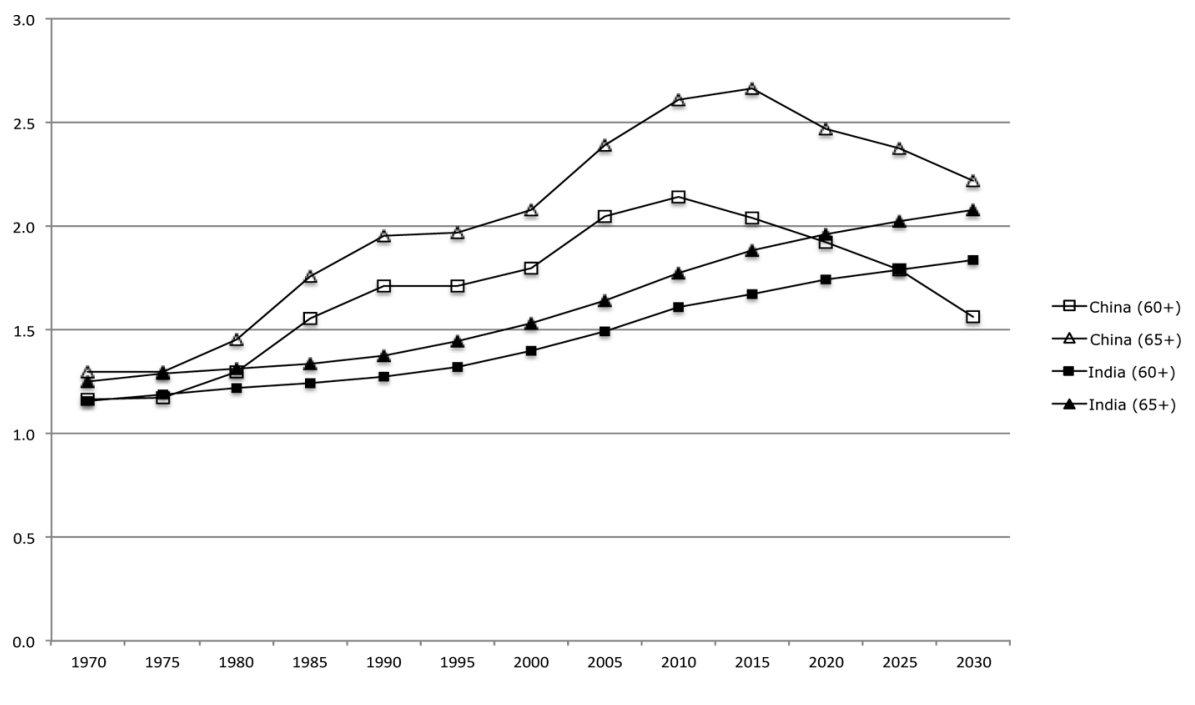

Source: United Nations (2010).

Note: Population projections based on medium fertility variant. Ratio is the working-aged (15-59 or 15-64 years) population divided by the non-working-aged (0-14 and 60+/65+ years).

youth (aged 0-14 years), working-aged ( $15-59$ years), and aged (60+ years) populations. There are numerous points of interest to our analysis here. First, the speed and compression of China's demographic transition relative to India's is quite visible in Figure 2, which shows the rapid decline in China's youth dependency through to 2010 and the commencement of rapid aging since then. This combination implies that China's total dependency ratio (defined here simply as the sum of youth and aged dependency) declined through to 2010 and is increasing thereafter-or, equivalently, that the proportion of its working-age population increased through to 2010 and is decreasing thereafter, as shown in Figure 3. In contrast, India's demographic transition is visibly much slower, with its total dependency ratio falling throughout the period 1970-2030, and with the peak of India's working-age to non-working-age ratio in 2035 being 25 years behind China's.

Although there are many factors that affect the timing and pace of each country's demographic transition, perhaps none do so more obviously than fertility. The early recognition (by development economists such as Coale and Hoover 1958) that a reduction in fertility in low-income countries would produce important economic benefits fed into the idea of a "population problem" and the need for population control as a means of promoting economic development in many developing coun- 
tries, including China, India, Pakistan, Taiwan, Thailand, Malaysia, Sri Lanka, Egypt, and Chile, all of which implemented a range of family planning policies from the 1950s onward.

For China, this culminated in the controversial one-child policy, which according to some estimates may have averted between 250 and 400 million births since its introduction in the early 1980s. ${ }^{3}$ This large range of averted birth estimates in part reflects ongoing controversies over just how far the fertility rate has fallen. Zhao (2011) and Zhao and Chen (2011) do some careful analysis to show that China's total fertility rates (TFR) for the periods 1995-2000, 2000-05, and 2005-10 were 1.6, 1.45, and 1.45, respectively. These figures contrast with those used in the UN's (2010) projections of $1.8,1.7$, and 1.64 for the same time periods, and also the official figures reported by the Chinese government (on which the UN's figures are based). Thus both Zhao and Chen (2011) and Zhao (2011) conclude that China's fertility rate is considerably lower than the officially reported level, and has been lower since the mid 1990s. ${ }^{4}$ Figure 4 illustrates the divergence between the TFR reported by the United Nations (2010), the Chinese government, annual survey data and Zhao and Chen's own revised rates. Zhao $(2011,54)$ rightly concludes that "[d]ifferences of nearly 20 percent in estimated fertility levels and of 100 million people in projected population size are by no means negligible."

It is less well known that India also implemented a range of family planning policies from the 1950s onward. Despite fairly rapid declines in the late 1990s in some southern states, Matthews et al. (2009) show that, overall, India has experienced a slow but steady decline in fertility rates, with some stagnation in recent years. In their analysis they consider the potential impact on population growth if India were to shift away from its focus on sterilization and toward something more akin to China's "fewer, later, longer" policy (adopted there in the 1970s) as a way of achieving more significant fertility decline in the future. ${ }^{5}$ Their population projections suggest that such a policy could reduce India's population by 52 million in 2050 compared with the current fertility trajectory.

3 For further details on China's population policies, and for estimates of averted births, see Sharping (2003), Liang and Lee (2006), and the National Family Planning and Population Commission of China (www.npc.gov.cn/pc/11_4/2011-03/10/content_1640532.htm, accessed 4 April 2011).

4 Zhang's (2007) case study provides further evidence of families in rural China shifting from "active resistance against" to "conscious decision for" the one-child limit.

5 Matthews et al. (2009) provide excellent details of India's population policies, and Padmadas et al. (2005) cover both countries. "Later, longer, fewer" refers to later marriage, longer gaps between children, and fewer births in total. 
Figure 4. Alternative estimates of China's total fertility rates

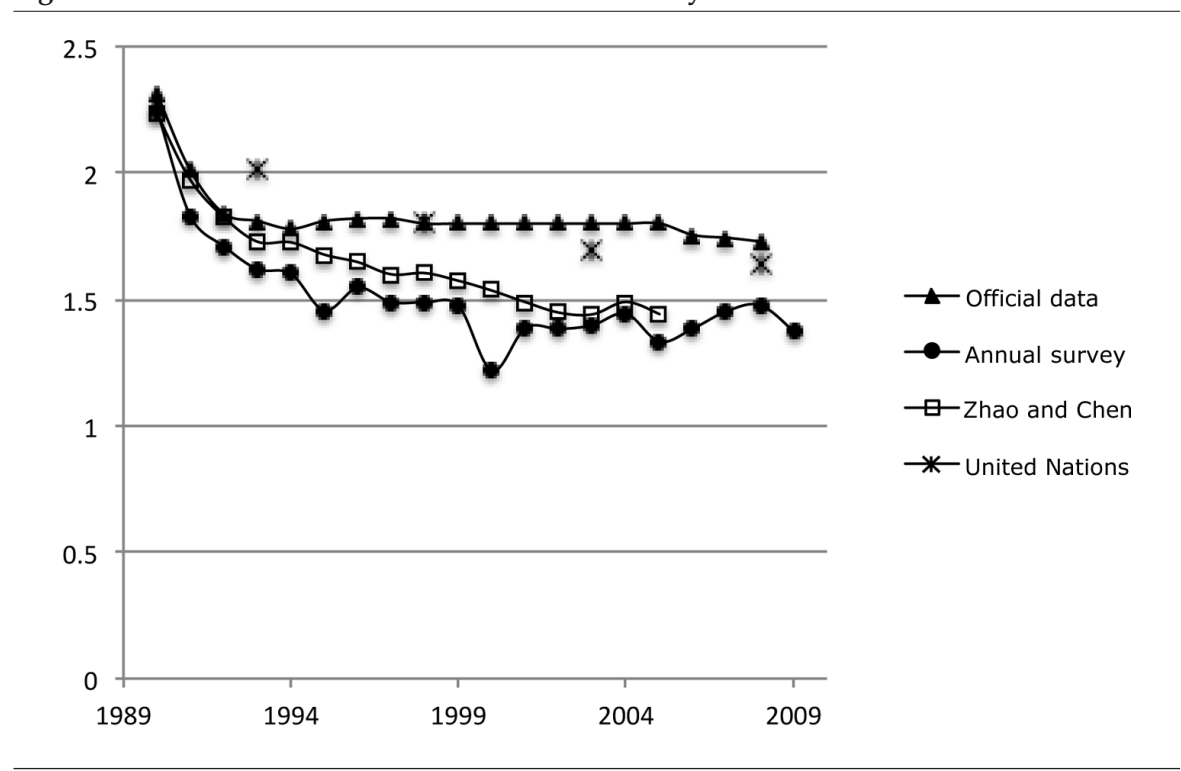

Source: Zhao and Chen (2011).

Of course, in both countries, as elsewhere, the independent impact of fertility policies is near impossible to separate. The uncertain link between policies and outcomes is just one of the reasons why fertility projections vary widely. For example, the United Nations (2010) projections for China's TFR in 2025-30 range from a "high fertility" variant of 2.08 down to a "low fertility" variant of 1.08. And the "high fertility" variant of the United Nations (2010) population projections implies that India's TFR will fall to 2.65 in 2025-30, whereas according to Dyson's (2002) "low fertility" variant it will reach 1.59 by that time. Regardless of which of these projections turns out to be correct, the key point is this: The effects of demographic transitions are shaped by a range of factors that impact on population structure and labor force participation, of which fertility rates are just one.

There are numerous channels through which demographic transition, precipitated by fertility decline, affects economic growth. One of the key predictions of the standard Solow-Swan model of growth, which assumes diminishing factor returns and constant labor participation rates across an ageless population, is that slower population growth reduces GDP growth, but increases per capita income growth. ${ }^{6}$ In real-

6 See Solow (1956) and Swan (1956), and the detailed analytical review offered by Pitchford (1974, chap. 4). 
ity, as seen here, in a developing country with large numbers of dependent children, a fall in fertility not only slows population growth, it also reduces the total dependency ratio and raises the proportion of the working-aged population. This effectively boosts the basic Solow-Swan impact on income per capita, giving rise to the demographic dividend. ${ }^{7}$

In addition to these supply-side effects, changes in age distributions also have demand-side implications, including changes in the scale and product composition of final consumption and saving rates. Additional complexities include the link between labor force growth, capital returns, and foreign investment, and the interdependence of fertility, longevity, labor force participation, and savings rates, which are in turn connected to policies affecting health, welfare, and pension systems. ${ }^{8}$ We take into account many, although not all, of these complexities in the model presented here.

\section{Modeling dependencies, dividends, and economic growth}

The approach adopted follows Tyers and Shi (2007), in that a complete demographic sub-model is integrated within a dynamic numerical model of the global economy. The baseline scenario represents a "business as usual" projection of global demographic change and economic growth through to 2030. Our focus in subsequent sections is on the extent of departures associated with alternative assumptions about demographic change in China and India. Nonetheless, we first describe the baseline to make clear the common set of assumptions about future trends in key exogenous variables and to make the construction of departures from it discernible. A more detailed description of the model can be found in Tyers and Golley (2010).

\section{I Demographic change}

Each region represented in the model includes four age groups, two sexes, and two skill categories, for a total of 16 population groups in each of 18 regions, two of which are mainland China and India. The four age groups are the dependent young, adults of fertile and working age, older working adults, and the mostly retired over 60s. The skill subdivision is between households that provide unskilled labor and skilled labor, with the former being transformed into the latter through time in

7 This can easily be seen by the simple decomposition of per capita income $(\mathrm{Y} / \mathrm{N})$ into per worker income $(\mathrm{Y} / \mathrm{W})$ times the working-age proportion of the total population $(\mathrm{W} / \mathrm{N})$, where $\mathrm{Y}$ is total income, $\mathrm{N}$ is total population, and $\mathrm{W}$ is the working-age population. See Bloom and Canning (2005a) for a clear exposition.

8 See, for example, Bloom and Canning (2005b), Heller (2006), and Bloom et al. (2007), and a more detailed discussion of their findings in Golley and Tyers (2011). 
response to changes in skilled wage premia, skilled shares of labor forces, and real per capita income.

Each age-sex-skill group is a homogeneous subpopulation with group-specific birth and death rates and rates of both immigration and emigration. If the group spans $T$ years, the survival rate to the next age group is the fraction $1 / T$ of its population, after group-specific deaths have been removed and its population has been adjusted for net migration. The final age group $(60+)$ has duration equal to measured life expectancy at 60 , which varies across sexes and regions. Birth rates, life expectancy at 60 , and age-specific death rates all trend through time asymptotically, approaching a target at a rate of growth determined by historical observation. Birth rates are here defined as the number of births per year per thousand women of fertile age. They are modified to allow for the modeling simplification that the fertile age group spans ages 15-39 years. Implied TFR are then calculated as the average number of children born by a woman throughout her life. China's baseline TFR remains fairly steady, beginning at 1.9 in 1997 and reaching 1.8 by 2030, midway between the United Nations (2010) medium and high fertility projections. ${ }^{9}$ For India, the base year TFR of 3.5 trends asymptotically to a target of 2.5, slightly lower than the United Nations (2010) high fertility projection for India.

\subsection{Defining dependency}

The definition of a population's total dependency ratio and its components is essential to projections of its demographic dividend. We consider the number of full-timeequivalent (FTE) workers, rather than the working-aged population, to be the most appropriate measure of the labor force on which these ratios are based. The total dependency ratio is then the ratio of the number of people not participating in labor markets to the number of FTE workers.

To evaluate the number of FTE workers, we first construct labor-force participation rates by age group, sex, and region from International Labor Organization statistics on the economically active population. We then investigate the proportion of workers that are part time and the hours they work relative to each regional standard for full-time work. The result is the number of FTE workers. Labor-force participation rates for each age-sex group and region are assumed to asymptotically approach the rate of a target country considered "advanced" in terms of trends in labor-force participation. Where female participation rates are rising, Norway provides a com-

9 We are convinced by the analysis of Zhao (2011) and Zhao and Chen (2011) that even the United Nations (2010) medium fertility variant is too high. We nevertheless choose this figure as our baseline to facilitate a meaningful comparison with lower fertility, a scenario we examine subsequently for both China and India. 
Table 1. Age-sex-specific participation rates in China and India, base year (1997) and projected (2030)

\begin{tabular}{|c|c|c|c|c|}
\hline \multirow{2}{*}{$\begin{array}{l}\text { Full-time-equivalent } \\
\text { workers per person }\end{array}$} & \multicolumn{2}{|l|}{ China } & \multicolumn{2}{|l|}{ India } \\
\hline & Males & Females & Males & Females \\
\hline \multicolumn{5}{|l|}{$15-39$} \\
\hline Initial (1997) & 0.79 & 0.60 & 0.81 & 0.35 \\
\hline 2030 & 0.77 & 0.61 & 0.83 & 0.36 \\
\hline \multicolumn{5}{|l|}{$40-59$} \\
\hline Initial (1997) & 0.91 & 0.43 & 0.95 & 0.38 \\
\hline 2030 & 0.93 & 0.45 & 0.96 & 0.40 \\
\hline \multicolumn{5}{|l|}{$60+$} \\
\hline Initial (1997) & 0.24 & 0.04 & 0.55 & 0.14 \\
\hline 2030 & 0.27 & 0.08 & 0.55 & 0.15 \\
\hline
\end{tabular}

Source: Values to 1997 are from United Nations (2000). For splits by skill level see Tyers and Bain (2006).

Note: Projections of these parameters to 2030 assume convergence on target rates observed in comparatively "advanced" countries. Only the end-point values are shown here but the model uses values that change with time along the path to convergence. Note also that these are averages over the skilled and unskilled categories. In the case of China participation by skilled (educated) women is much higher than for unskilled, particularly for ages 40+, contributing an extra percent to the 2030 average.

monly chosen target because its female labor force participation rates are higher than for other countries.

For China and India, the trends in the baseline labor force participation rates are summarized in Table 1. China's aged labor-force participation is assumed to rise slightly to allow for the expected shortfall in pension income as more retirees leave private sector employment. India has substantially higher aged participation rates, lacking China's central planning history. The other striking pattern is that India's female labor force participation rates are considerably lower in the main working age group (ages 15-59 years) than those in China. ${ }^{10}$

We identify three components of the total dependency ratio based on the age-sex groups in the model. The first is the youth dependency ratio, defined as the number of dependent children per FTE worker. The second is the aged dependency ratio, in which the numerator comprises only the non-working population over 60 . This can be different from the more conventional aged dependency ratio depending on aged labor force participation. The third is the working-aged dependency ratio, in which the numerator comprises the non-working population of working age (15-59 years). It is important to note that this ratio is excluded from the standard definition of the "dependency ratio" altogether. The sum of these three dependency ratios indicates the number of non-working people of all ages and sexes per full-time-equivalent

10 We acknowledge the comments by Sisira Jayasuriya that India's female labor force participation rates are in fact much higher than the official figures, given the large numbers of women engaged in non-paid work in rural areas. Unfortunately we do not have access to data that can allow a more accurate representation along these lines and remain consistent with the measurements used by other countries. 
Table 2. Dependency and dividend ratios, initial and baseline projection to $2030(\%)$

\begin{tabular}{llll}
\hline & & China & India \\
\hline Youth / working & Initial & 0.59 & 0.93 \\
& 2030 & 0.39 & 0.62 \\
Non-working-aged / working & Initial & 0.18 & 0.12 \\
& 2030 & 0.38 & 0.24 \\
Non-working of working age / working & Initial & 0.45 & 0.63 \\
Total dependency ratio: non-working / working & 2030 & 0.40 & 0.54 \\
& Initial & 1.22 & 1.68 \\
Dividend ratio: inverse of total dependency & 2030 & 1.15 & 1.29 \\
& Initial & 0.82 & 0.60 \\
\hline
\end{tabular}

Source: The base period ratios are constructed from population statistics from United Nations (2005) and those for 2030 from simulation results described in the text.

Note: The dependency ratios may be read as the number of dependents per full-time-equivalent worker, and the dividend ratios give the number of full-time-equivalent workers per dependent.

worker, and gives our total dependency ratio. We then define the dividend ratio as the inverse of this. ${ }^{11}$

Baseline projections of these total dependency ratios and their components for China and India are shown in Table 2. Notably, one of the largest dependent groups comprises those of working age who are not participating in the labor market. This is due, in part, to education participation by those over 15, in part to disablement, and in part to home-making partners. The simulated changes to 2030 show the expected declines in youth dependency as fertility declines, with a more dramatic drop for India. The associated aging boosts aged dependency, with the non-working aged dependency ratio close to doubling in both countries, albeit from a lower base in India. Declines in youth dependency more than offset rises in aged dependency in both regions but the difference is larger for India. Inverting the total dependency ratios yields dividend ratios that are higher for China (more workers per dependent) but rising much faster for India. The declines in non-working working-age dependency are due primarily to aging of the female labor force.

This raises one of the key points of this paper. According to the commonly used measures of dependency (based on United Nations projections of age structures), China's total dependency ratio is predicted to increase beyond 2010, as shown in Figure 3, giving rise to claims that China will enter a period of "demographic taxation" soon thereafter. Even with the ADB's more refined "economic support ratio," this taxation kicks in around 2020. And yet, when the true number of "dependents" is taken into account, as in Table 2, we see that in fact China's dependency ratio is

11 See Golley and Tyers (2011) for the equations used to calculate these ratios. 
actually lower (and its dividend ratio higher) in 2030 than it was in 2000. Rising aged dependency is thus projected to take considerable time to overtake the effects of declining youth dependency and this process is projected to be incomplete by 2030 .

\subsection{Economic growth}

The model of the global economy that embodies the demographic behavior discussed previously considers each region to contribute seven industries: agriculture, light manufacturing, heavy manufacturing, metals, energy, minerals, and services. To reflect compositional differences between regions, these products are differentiated by region of origin, meaning that the "light manufactures" produced in one region are not the same as those produced in others. Consumers substitute imperfectly between manufactures from different regions.

To capture the full effects of demographic change, the multiple age, sex, and skill groups are modeled as separate households. These 16 groups differ in their shares of regional disposable income, consumption preferences, savings rates, and their labor supply behavior. While the consumption-savings choice differs for each age-sex group, it is dependent for all on current group-specific real per capita disposable income and the real lending rate. Governments balance their budgets and private groups save or borrow.

As in other dynamic models of the global economy, the main endogenous driver of simulated economic growth is physical capital accumulation. The transformation of workers from unskilled to skilled is another driving force in this model. What distinguishes the model from its simpler progenitors is the endogeneity of saving rates and its multiregional structure. All regional capital accounts are open and investors have adaptive expectations about real regional net rates of return on installed capital. These drive the distribution of investment across regions. In each, the level of investment is determined by a comparison of net rates of return on domestic installed capital with borrowing rates yielded by a global trust, to which each region's saving contributes, adjusted by calibrated region-specific interest premia.

In addition to the endogenous drivers of growth, there are several sets of exogenous shocks that the baseline and all other simulations have in common: 1) exogenous technical change, which is specific to primary factors and industries, 2) time-varying risk premia ensure that all new investment is not directed merely to the most populous regions which would otherwise have the highest marginal products of capital, and 3) idiosyncratic shocks to risk premia and investment productivity are introduced to represent the global financial crisis (Tyers and Bain 2008). 
Consumption-savings preferences are represented by age-sex-skill-specific consumption equations that relate real per capita consumption to real per capita income and the real lending rate in each region. There is no endogeneity of saving rates to life expectancy at 60 even though death rates decline through time and life expectancy increases in both nations. Group saving rates change in response to changes in income and interest rates but, more importantly, regional average saving rates respond to changes in age and skill distributions. As a young population ages, the proportion of its population in the saving age groups rises and so does its average saving rate. In the case of an old population, further aging raises the proportion of non-working aged, and so its average saving rate falls. The Chinese $60+$ age group is unusual, at least through the 1990s, in that it has low labor force participation but high state-financed retirement incomes. The pensions, combined with low consumption expenditures due to extended family sharing, lead to high initial retiree saving rates. Yet because the proportion of the aged retiring on relatively generous state pensions is declining, the $60+$ groups are assumed to have underlying savings rates that fall through time. In the case of India, we have no a priori reason to think that the underlying saving rates will rise or fall, and so these are held constant.

\subsection{Baseline projections for China and India}

The baseline population and labor force projections for both China and India are illustrated in Figure 5 and the associated changes in the age and sex structure of each are summarized in Table 3. A dramatic contrast between the projections for China and India is clear from Figure 5. Whereas China's labor force falls short of a 13 percent increase over the three decades, and declines after 2025, the Indian labor force grows strongly, with expansion continuing beyond 2030. This contrast is primarily due to the relative youth of India's population and its higher initial fertility rate. Even though the two populations are projected to reach rough parity in 2030, the Indian labor force remains smaller, due mainly to lower female participation rates. Accordingly, the projected Indian labor force has proportionally more male workers. Interestingly, the more rapid aging of China's population notwithstanding, the projected labor forces of the two nations maintain similar proportions of older workers. This is explained by India's comparatively high participation rates of $60+$ workers, which are close to double China's for both men and women.

\section{Alternative demographic scenarios}

\section{I Lower fertility}

To reflect the recent findings of Zhao (2011) and Zhao and Chen (2011), we first examine the implications of lower fertility in China. In particular, we assume that 
Figure 5. Projected populations and labor forces, China and India (cumulative percent departures from baseline)

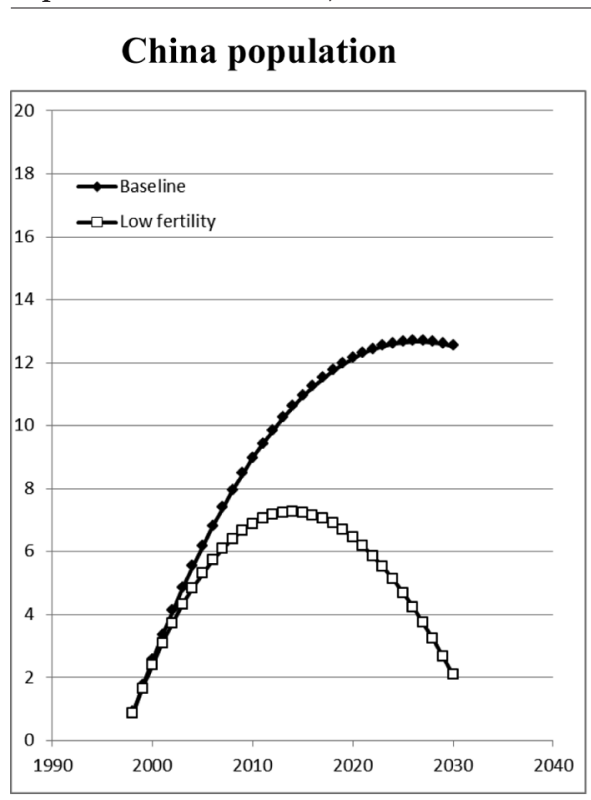

\section{China labor force}
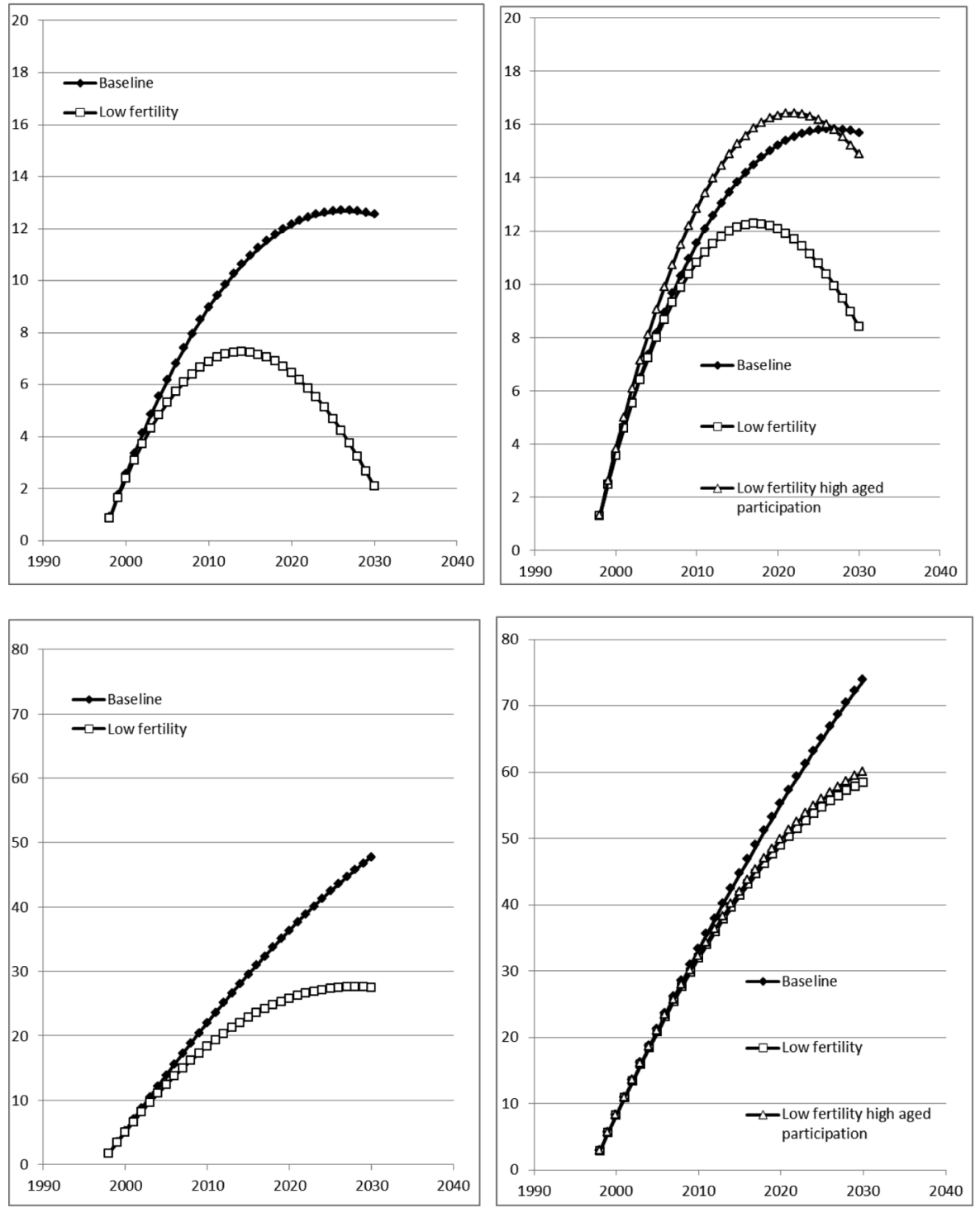

Source: Authors' calculations.

Note: These are cumulative percent departures from the base year 1997, drawn from the baseline simulation in which India commences with a much younger population. 
Table 3. Baseline population and labor force structure in China and India

\begin{tabular}{|c|c|c|c|c|c|c|}
\hline \multirow[b]{2}{*}{ Population } & \multicolumn{3}{|l|}{ China } & \multicolumn{3}{|l|}{ India } \\
\hline & Millions & $\%$ female & $\% 60+$ & Millions & $\%$ female & $\% 60+$ \\
\hline Initial (1997) & 1,272 & 48.5 & 9.7 & 955 & 48.2 & 6.9 \\
\hline 2010 & 1,364 & 48.7 & 14.8 & 1,146 & 48.4 & 10.6 \\
\hline 2020 & 1,375 & 48.8 & 18.4 & 1,263 & 48.5 & 13.0 \\
\hline 2030 & 1,353 & 49.0 & 21.2 & 1,349 & 48.5 & 14.8 \\
\hline Labor force & & & $\% 40+$ & & & $\% 40+$ \\
\hline Initial (1997) & 570 & 37.2 & 33.9 & 356 & 27.4 & 36.3 \\
\hline 2010 & 618 & 36.7 & 41.2 & 459 & 27.1 & 41.7 \\
\hline 2020 & 624 & 36.4 & 45.4 & 522 & 27.2 & 45.1 \\
\hline 2030 & 613 & 36.1 & 48.2 & 568 & 27.5 & 47.9 \\
\hline
\end{tabular}

Source: Projection using the baseline simulation of the model described in the text. The labor forces are measured in full-time-equivalent workers.

China's average TFR falls over the three decades from the same 1997 level of 1.9 down to 1.1, consistent with the United Nations (2010) low fertility variant. ${ }^{12}$ The implications for population and labor force growth are displayed graphically in Figure 5. Critically, the path of China's labor force shifts down by substantially less than that of its population. By 2030, the labor force is smaller by six percent and the population by ten percent. This is because lower fertility first reduces the youth population, which does not impact on the labor force but does reduce dependency. China's population continues to age, however, and more rapidly with the lower fertility rate. Although this results in an increasing non-working-aged dependency, this is dominated by the fall in youth dependency, ensuring that total dependency falls through to 2030, as shown in Figure 6.

The economic effects reflect many of the points made in Section 3. In particular, supply-side labor-force effects are dominant. The anticipated supply-side story is that the number of workers contracts, reducing capital productivity, and therefore reducing the return on Chinese investment. This draws more of the world's savings out of China so that its capital stock grows more slowly. China's GDP might therefore be expected to fall substantially because of lower fertility, through its direct and indirect influence over the supply of the two main factors of production, labor and capital. ${ }^{13}$ In per capita terms, however, three forces conspire to ensure that the aver-

12 The model allows for different TFRs in the skilled and production worker populations. The numbers presented here, and for the subsequent Indian scenario as well, are the weighted averages of these two sub-populations, with the shocks to the target levels of fertility in each being proportionally the same.

13 This result could have a number of economic implications that are not captured in our model, including that higher fertility might reduce pressure on fiscal policy and so the growth-retarding effects of tax distortions might be reduced. Our scenarios maintain constant tax rates and fiscal deficits. 
Figure 6. Total dependency ratios (non-working over working)
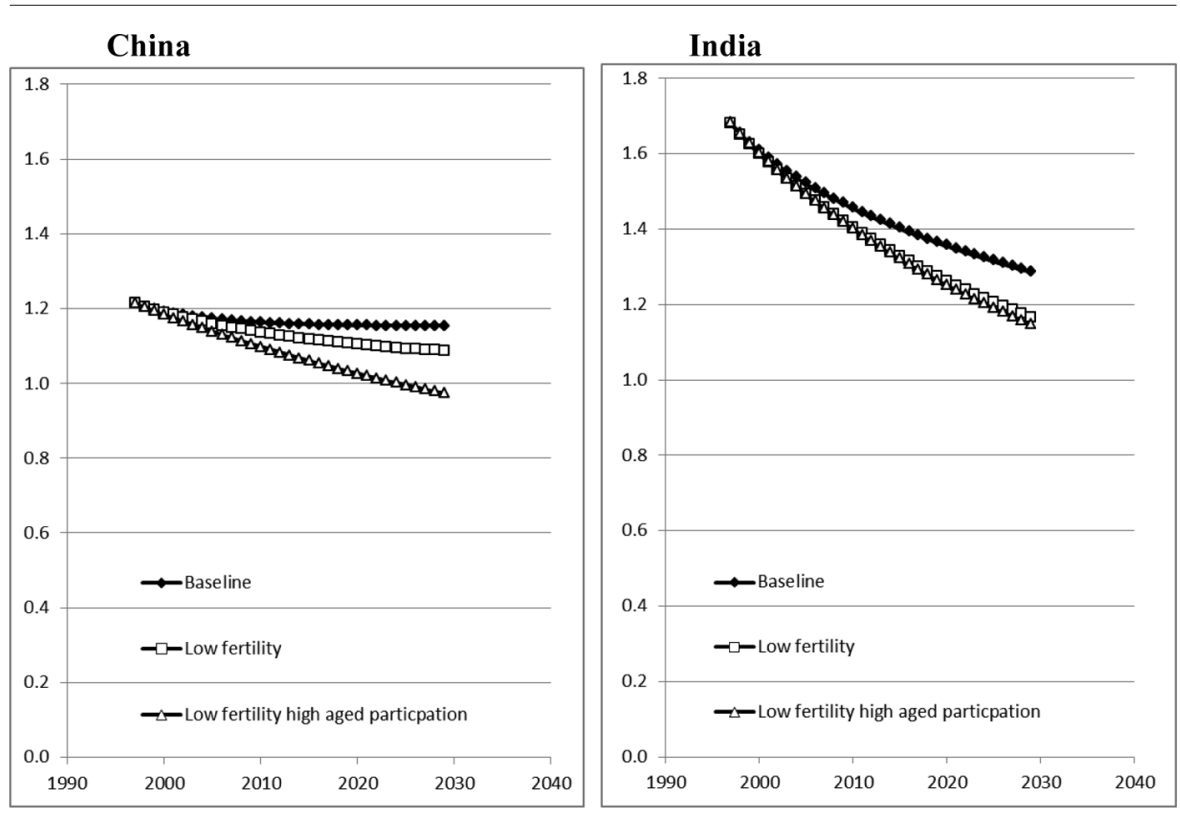

Source: Model simulations described in the text.

Note: These are the simulated ratios of the total non-working-working population and the full-time-equivalent labor force. The declines in dependency in both cases represent primarily declines in youth dependency.

age Chinese person benefits. First, the Solow-Swan predisposition (due to diminishing marginal returns) toward higher real wage growth in response to the reduction in labor supply increases the growth of income per capita. Second, the associated shift in the age distribution causes a fall in dependency and hence a further increase in per capita income growth. Finally, because much of the capital outflow stems from foreign investment, there would be a reduction in the need to reward foreign owners. In the end, China's 2030 real per capita income is higher by 7.4 percent, as shown in Figure 7.

We then conduct a lower fertility scenario for India, which embodies a fall in the average TFR to 1.6 by 2030, compared with 2.5 in the baseline simulation and similar to Dyson's (2002) "low fertility" variant. This reflects the potential for (even if not the realization of) family planning polices to bring India's fertility rates down more rapidly in the next two decades. As shown in Figure 5, this yields substantial slowdowns in both the population and the labor force. As in the fertility shock to China, the effect on the population is proportionally larger than that on the population. 
Figure 7. Effects of demographic change on real per capita income

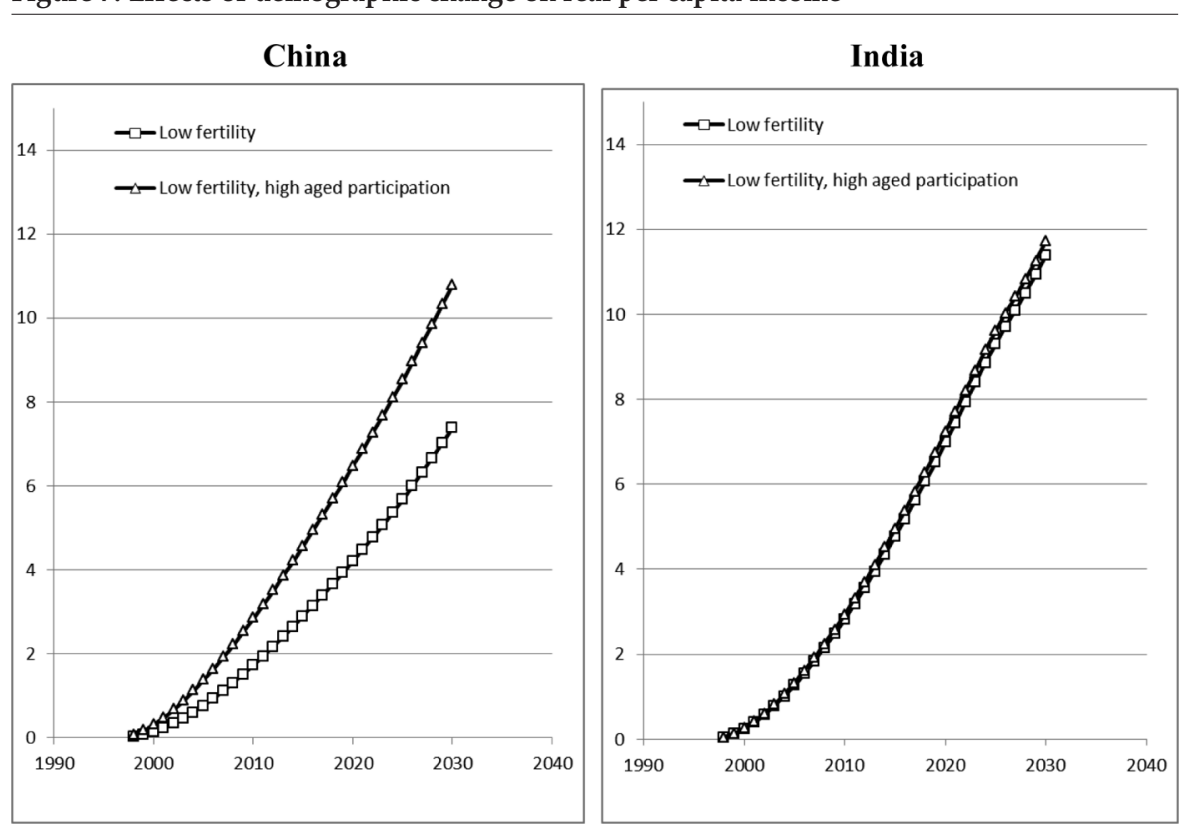

Source: Simulations of the model described in the text.

Note: These are percent departures from the baseline simulation.

Again, this is because fertility changes first affect the youth population, and not those of working age. In contrast with China, however, in India the difference is even larger because of its relatively young population, its large population of women of fertile age, and its high, aged labor-force participation rates. As shown in Figure 6, the diminished slowing impact on the labor force results in a substantial decline in the total dependency ratio, which is the combination of a minimal rise in non-working-aged dependency combined with a dramatic decline in youth dependency. Critically, by 2030, although there is a decline in Indian GDP relative to the baseline, the corresponding gain in real per capita income is 11.4 percent, as shown in Figure 7.

\subsection{Higher aged labor force participation}

These two simulations illustrate the often-neglected point that the economic effects of demographic change depend on a range of variables, total fertility being only the most obvious. ${ }^{14}$ The dominance of the labor-supply (relative to the saving and con-

14 Death rates are also obvious determinants, though these have had more stable declining 
sumption mix) effects of demographic change on the economy ${ }^{15}$ suggests that laborforce participation rates are also critical. We demonstrate this here by considering the impact of delayed retirement and hence higher participation rates by China's and then by India's aged $(60+)$ population. As seen in Table 1, the baseline participation rates for China's aged population in 1997 and 2030 are low; with rates that are projected to be little more than half of India's in 2030 for both men and women and that are low by other East Asian standards (Golley and Tyers 2006).

There are, however, numerous reasons why China's labor-force participation rates could be higher in the future. Perhaps the most obvious of these is increased aged participation and hence a rise in the average retirement age. In an influential World Bank (1997) report on China's social security system, it is noted that current retirement ages of 60 for men and 55 for women were set at a time when life expectancy was only 50 years, compared with 71 years now. The report called for a gradual increase in the retirement age to 65 years and even higher as longevity continues to increase. But mandated retirement ages only affect workers in government and large regulated private institutions. Much of China's growth in recent decades has been associated with the formation of private and family businesses and, in this private world, the incentive to continue working beyond 60 is stronger (see Golley and Tyers 2006).

To reflect this possibility, we next consider a simulation in which China's average aged participation rates rise through 2030, from about 30 percent to 43 percent for men and from 5 percent to 25 percent for women. ${ }^{16}$ This simulation continues to assume that lower fertility rates also prevail, consistent with the "low fertility" scenarios discussed previously. Although changes in participation rates have no direct impacts on total populations, they clearly affect the growth of the labor force, as shown in Figure 5. Even when combined with low fertility, higher aged participation can raise China's overall labor force above its baseline level through to 2025. It dives below the baseline level thereafter only because the $60+$ participation rate converges on a target level from below and, as this occurs, the effects of lower fertility are again dominant.

Increases in real GDP and real per capita income are obvious consequences of higher aged participation in the workforce, though these aggregate advantages are at least

trends in China and India, and as they are assumed to continue in all simulations they are not discussed further here.

15 See Tyers and Shi (2007) for evidence of this.

16 Recall that these are weighted averages of simulated participation rates that differ for professional (skilled) workers and production (unskilled) workers. 
partially offset by the loss of leisure time and lower real wages. Nonetheless, these downsides of increased participation are in part counterbalanced, particularly in the expanding services sector, by the benefits of continued social engagement and learning. ${ }^{17}$

Our final simulation focuses on raising India's aged participation rate. For India, however, official statistics suggest aged participation is already high, particularly among males, and so the changes are more marginal and directed to female participation. Whereas our baseline had male participation rising from 55 percent to 60 percent by 2030 and from 14 percent to 22 percent for women, here we consider a scenario in which female participation rises to 30 percent by 2030. As expected, this more modest change yields far smaller effects than the larger shocks to participation imposed in the Chinese case, as shown in Figures 5-7. The additional impact on India's labor force is only slightly above the trajectory for low fertility alone (Figure 5), and the consequent reduction in total dependency is minimal, particularly compared with China (Figure 6). This contributes to an increase in India's real per capita income of 11.7 percent by 2030, compared with 11.4 percent for fertility reduction alone, whereas China's real per capita income increases by nearly 11 percent, compared with just 7.5 percent for the low fertility scenario.

\subsection{China's and India's demographic dividends, 1997-2030}

As discussed earlier, the economic effects of the modeled demographic changes combine three stories. First, the Solow-Swan effect of population slowdown (and hence higher marginal products due to diminishing factor returns) leads to real growth in per capita terms. Second, the shift in age distribution away from dependent children toward the working ages also causes real growth in per capita terms (as each worker has fewer dependents to spread his/her income across). Third, increased labor force participation also raises output in per capita terms. Moreover, increased participation also enhances the second effect, age distribution, by enlarging the rise in the labor force due to the movement of the dependent young into working age.

To isolate the pure effects of changes in age distributions-that is, the demographic dividends-a variant of the model is constructed in which the endogenous demographic behavior is switched off and the populations in each age group are constrained to follow exogenous and identical time paths. This ensures that age distributions are held fixed through time. The resulting simulations therefore pick up the

17 These tradeoffs will clearly differ from person to person based on their preferences for labor, leisure, social engagement, and learning. 
Figure 8. Demographic dividends: Age distribution components of demographic effects on real per capita income
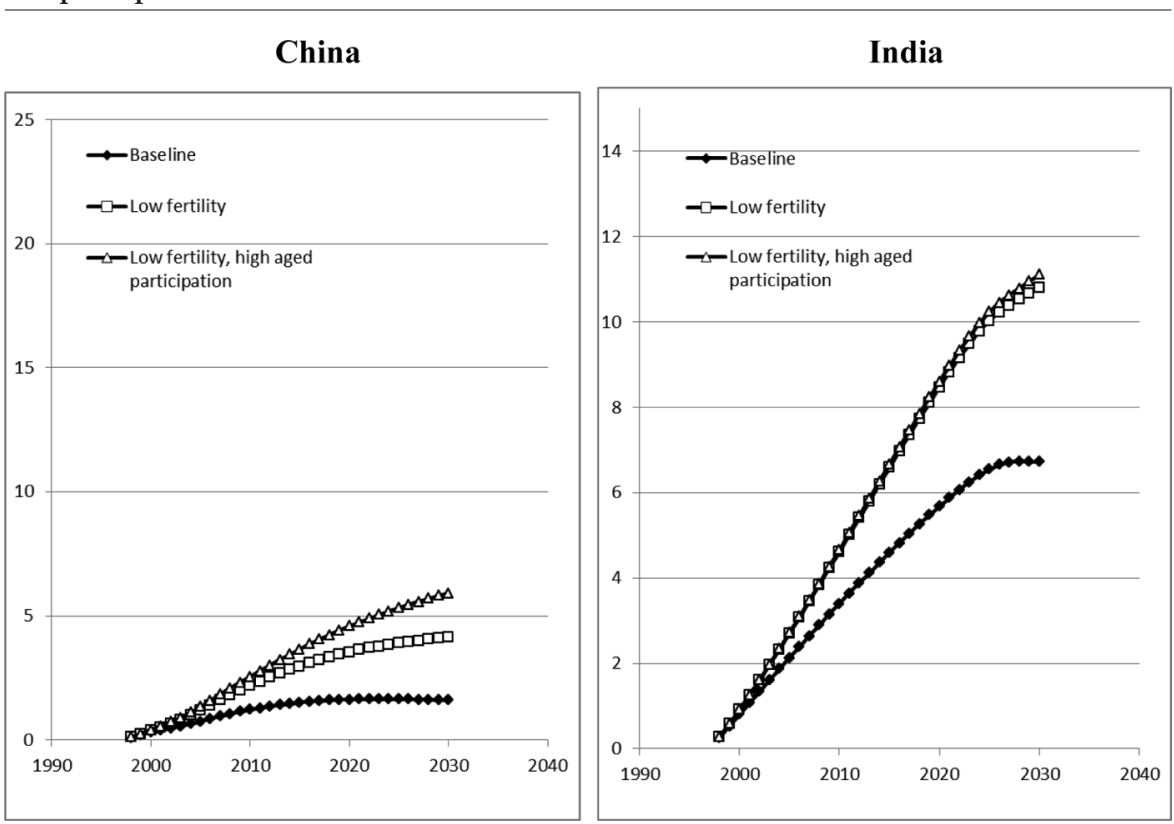

Source: Simulations of the model described in the text.

Note: These are contributions to real per capita income growth, measured here as cumulative percent departures from the base year 1997. They are calculated by comparing full simulations under each of the three scenarios with corresponding simulations in which the total population follows the same time path but there is no change in the age distribution.

Solow-Swan effects of (now exogenous) slowdowns in population growth, combined with any growth in labor force participation, which serve to raise real per capita income, but they exclude the effects of changes in age distributions.

For each of our three scenarios (baseline, low fertility, and low fertility with increased aged participation) we take the post-1997 annual population changes from the simulation with full demography and then, in the comparator, we switch off the demography and all age groups are made to follow these now exogenous time paths. We then consider the original simulation, with its full demography, as a departure from the "fixed-age distribution" comparator. For each of the three scenarios we make one such comparator simulation for China and, separately, one for India, in each case extracting the effect of age distribution change by subtracting the comparator results for real per capita income from those drawn from the simulation with full demography. The result is a measure, for each scenario, of the post-1997 
demographic dividend-the contribution to the enlargement of real per capita income since 1997 that is solely due to the changing age distribution. The resulting dividends are illustrated in Figure 8.

In the baseline case, the aging that occurs through 2030 raises the proportion of the population engaged in work and so raises real per capita income. India starts the new millennium with considerably more youth dependency than China and so aging moves this youthful abundance into working age and therefore reduces overall dependency. The result is a gain of 6.7 percent in real per capita income over the three decades. China, too, has mostly youth dependency but, by 2000 , there is much less than in India and so aging is less beneficial, delivering a post-1997 demographic dividend that stabilizes at 1.6 percent in real per capita income through to 2030 .

For China, then, the principal economic effect of its population slowdown is SwanSolow, with a smaller labor force yielding higher per capita income. Still, the fact that China continues to receive a positive demographic dividend through to 2030, albeit a small one, contrasts with recent claims that the end of its demographic transition, and hence its demographic dividend, is imminent. This point is further emphasized by the demographic dividends under China's lower fertility and higher aged participation rate scenarios, which increase to 4.1 and 5.9 percent of real per capita income, respectively.

The comparison that gives rise to these estimates enables the decomposition of the rise in China's real per capita income due to fertility decline and increased aged participation after 1997, as shown in Table 4. The contribution of the Swan-Solow effect is the largest, accounting for 44 percent of the total increase in real per capita income, and that of the demographic dividend comes in second, accounting for 22 percent of the income rise. Thus, although the demographic dividend is not the major contributor to economic gains from slower population growth, it is still a substantial contributor. Combined with the indirect effect via increased participation, the contribution of the change in age distribution almost equals that of the SwanSolow effect.

For India, Figure 8 illustrates the potential for a significant demographic dividend in the future should fertility continue to decline. Compared with a baseline demographic dividend of just over 6 percent of real per capita income, lower fertility is projected to deliver a real per capita income gain of 11.7 percent by 2030 . Higher aged participation in India has a modest additional effect because it is assumed only to alter participation by aged women and by a comparatively small margin. As indicated in Table 4, the Swan-Solow effect is the dominant demographic force in India 
Table 4. Decomposition of 1997-2030 demographic effects on real per capita income

\begin{tabular}{lcc}
\hline & China & India \\
\hline Swan-Solow effect & 4.9 & 7.3 \\
Age distribution (demographic dividend): direct & 2.5 & 4.1 \\
Age distribution interaction with aged participation: indirect & 1.8 & 0.2 \\
Aged participation & 1.8 & 0.1 \\
\hline Total & 11.0 & 11.7 \\
\hline
\end{tabular}

Source: Projections using the model described in the text.

Note: This requires a comparison of the standard baseline, and low-fertility and low-fertility high-aged participation scenarios with their corresponding comparator versions that lack age distribution change.

as it is in China, contributing 62 percent of the increase in real per capita income. Nonetheless, the remainder is dominated by the demographic dividend, which delivers another 35 percent.

\section{Conclusions}

Population structure plays a critical role in determining the relative magnitudes of labor force growth and total population growth and the consequent change in dependency ratios, which in turn impact significantly on per capita income growth. In particular, the decline in fertility rates since the 1950s has reduced total population growth and dependencies in both China and India, precipitating higher per capita income growth, or demographic dividends, in both cases. Given their different population age structures, it comes as no surprise that the timing and magnitude of China's and India's demographic dividends have also differed: China's largely lies in the past whereas India's lies in the present.

Using accurate measures of the working population (rather than the working-aged population) to calculate dependency, however, reveals that China's demographic dividend (due to age distribution changes since 2000) is in fact projected to remain positive through to 2030, contrary to the claims of others. More critically, this "true" dependency ratio reflects the actual benefits from having a rising share of workers in the population, rather than the potential benefits of having a rising share of the merely working aged. Our findings do not refute the empirical stream of work that highlights the significance of the demographic dividend as a key determinant of economic growth. Rather they reinforce it, because age distribution effects are larger, particularly in China's case, when trends in participation rates are properly accounted for.

In both China and India, it is quite plausible that fertility decline will happen more rapidly in the decades ahead, with recent evidence suggesting that China's fertility 
rate has already fallen much further than official (and therefore United Nations) reports indicate, and with India actively trying to promote more rapid fertility decline. Our simulations show that lower fertility reduces GDP and increases real per capita income in both countries, although India gains substantially more per capita income than China per unit change in fertility, a result that depends critically on India's higher youth dependency. Similarly, simulations that raise aged labor force participation rates in both countries are shown to increase per capita income, with China not surprisingly standing to gain more, given its relatively aged and more rapidly aging population, and its comparatively low rates of aged labor force participation.

These alternative simulations indicate clearly that the magnitude of both China's and India's future demographic dividends depend on a range of factors, of which policies that impact on fertility rates and labor force participation are just two.

\section{References}

Asian Development Bank. 2011. Asian Development Outlook 2011 Update. www.adb.org/sites/ default/files/adu2011.pdf. Last accessed 27 June 2012.

Bloom, David E., and David Canning. 2005a. Global Demographic Change: Dimensions and Economic Significance. In: Global Demographic Change: Economic Impacts and Policy Challenges. A symposium sponsored by the Federal Reserve Bank of Kansas City, 26-28 August 2004. www.kansascityfed.org/publications/research/escp/escp-2004.cfm. Last accessed 27 June 2012.

Bloom, David E., and David Canning. 2005b. The Effect of Improvements in Health and Longevity on Optimal Retirement and Saving. NBER Working Paper No. 10919. Cambridge, MA: National Bureau of Economic Research.

Bloom, David E., David Canning, Günther Fink, and Jocelyn Finlay. 2007. Fertility, Female Labor Force Participation and the Demographic Dividend. NBER Working Paper No. 13583. Cambridge, MA: National Bureau of Economic Research.

Bloom, David E., David Canning, and Pia N. Malaney. 2000. Population Dynamics and Economic Growth in Asia. Population and Development Review Supplement: Population and Economic Change in East Asia 26:257-290.

Bloom, David, David Canning, and Jaypee Sevilla. 2002. The Demographic Dividend: A New Perspective on the Economic Consequences of Population Change. Santa Monica, CA: RAND, MR-1274.

Bloom, David E., and Jeffrey G. Williamson. 1998. Demographic Transitions and Economic Miracles in Emerging Asia. World Bank Economic Review 12(3):419-455.

Cai, Fang, and Dewen Wang. 2005. Demographic Transition: Implications for Growth. In: The China Boom and Its Discontents, edited by Ross Garnaut and Ligang Song, pp. 34-52. Canberra: Asia-Pacific Press.

Coale, Ansley J., and Edgar M. Hoover. 1958. Population Growth and Economic Development in Low-Income Countries: A Case Study of India's Prospects. Princeton, NJ: Princeton University Press. 
Dyson, Tim. 2002. On the Future of Human Fertility in India. In Completing the Fertility Transition, pp. 392-408. New York: United Nations.

Feng, Wang, and Andrew Mason. 2005. Demographic Dividend and Prospects for Economic Development in China. Paper presented at UN Expert Group Meeting on Social and Economic Implications of Changing Population Age Structures, 31 August-2 September, Mexico City.

Golley, Jane, and Rod Tyers. 2006. China's Growth to 2030: Demographic Change and the Labor Supply Constraint. In: The Turning Point in China's Economic Development, edited by Ross Garnaut and Ligang Song, pp. 203-226. Canberra: Asia-Pacific Press.

Golley, Jane, and Rod Tyers. 2011. Contrasting Giants: Demographic Change and Economic Performance in China and India. Centre for Applied Microeconomic Analysis Working Paper No. 10/2011. Canberra: Research School of Economics, The Australian National University.

Heller, Peter S. 2006. Is Asia Prepared for an Aging Population? IMF Working Paper No. WP/ 06/272. Washington, DC: International Monetary Fund.

Liang, Qiusheng, and Che-Fu Lee. 2006. Fertility and Population Policy: An Overview. In: Fertility, Family Planning and Population Control in China, edited by Poston, D. L., Jr, Che-Fu Lee, Chiung-Fang Change, Sherry L. McKibben, and Carol S. Walther, pp. 7-20. Oxford and New York: Routledge Studies in Asia's Transformations.

Matthews, Zoë, Sabu Padmadas, Inge Hutter, Juliet McEachran, and James Brown. 2009. Does Early Childbearing and a Sterilization-Focused Family Planning Programme in India Fuel Population Growth? Demographic Research 20(28):693-720.

National Bureau of Statistics. 2000. 1949-99 China Statistical Data Compilation. Beijing: NBS.

Padmadas, Sabu, Guangzhou Wang, James Brown, and Bohua Li. 2005. Birth Planning and Population Prospects in China and India. Paper presented at the IUSSP XXV International Population Conference, 18-23 July, Tours, France.

Pitchford, John D. 1974. Population in Economic Growth. Amsterdam: North Holland Publishing Co.

Sharping, Thomas. 2003. Birth Control in China 1949-2000: Population Policy and Demographic Development. London: Routledge Curzon.

Solow, Robert M. 1956. A Contribution to the Theory of Economic Growth. Quarterly Journal of Economics 70(1):65-94.

Swan, T. W. 1956. Economic Growth and Capital Accumulation. Economic Record 32(2):334-361.

Tyers, Rod, and Iain Bain. 2006 (revised September 2007). The Global Implications of Freer Skilled Migration. Working Papers in Economics and Econometrics No. 468. Canberra: Australian National University.

Tyers, Rod, and Iain Bain. 2008. American and European Financial Shocks: Implications for China's Economic Performance. In China's Dilemma: Economic Growth, the Environment and Climate Change, edited by Ligang Song and Wing Thye Woo, pp. 59-89. Beijing: Asia Pacific Press, the Brookings Institution Press, and Social Sciences Academic Press.

Tyers, Rod, and Jane Golley. 2010. China's Growth to 2030: The Roles of Demographic Change and Financial Reform. Review of Development Economics 14(3):592-610. [Earlier version in Chinese: 2007. China Labor Economics 4(1):6-30.] 
Tyers, Rod, and Qun Shi. 2007. Global demographic change, policy responses and their economic implications. The World Economy 30(4): 537-566.

United Nations. 2000. 1997 United Nations Demographic Yearbook. New York: UN Department of Economic and Social Affairs.

United Nations. 2005. World Population Prospects: The 2005 Revision. New York: UN Population Division.

United Nations. 2010. World Population Prospects: The 2010 Revision. New York: UN Population Division. Available at http://esa.un.org/wpp/unpp/panel_population.htm.

World Bank. 1997. China 2020: Old Age Security. Washington, DC: The World Bank.

Zhang, Hong. 2007. From Resisting to "Embracing"? The New One-Child Rule: Understanding New Fertility Trends in a Central China Village. The China Quarterly 192:855-875.

Zhao, Zhongwei. 2011. Reflections on China's Recent Population Statistics and Current Demography Situation. Chinese Cross Currents 8(3):44-57.

Zhao, Zhongwei, and Wei Chen. 2011. China's Far Below Replacement Fertility and Its LongTerm Impact: Comments on the Preliminary Results of the 2010 Census. Demographic Research 25(26):819-836. 